OPEN ACCESS

Edited by:

Rentian Feng,

University of Pittsburgh, United States

Reviewed by:

Christian Klein,

Roche Innovation Center Zurich,

Switzerland

Marco A. Velasco-Velazquez, National Autonomous University of Mexico, Mexico

*Correspondence:

Zhaoming Li

fcclizm@zzu.edu.cn

Tian Tian

fcctiant@zzu.edu.cn

Specialty section:

This article was submitted to

Cancer Molecular Targets and Therapeutics,

a section of the journal

Frontiers in Oncology

Received: 26 June 2021 Accepted: 07 September 2021 Published: 22 September 2021

Citation:

Tian T and Li Z (2021) Targeting Tim-3 in Cancer With Resistance

to PD-1/PD-L1 Blockade.

Front. Oncol. 11:731175. doi: 10.3389/fonc.2021.731175

\section{Targeting Tim-3 in Cancer With Resistance to PD-1/PD-L1 Blockade}

\author{
Tian $\operatorname{Tian}^{1 *}$ and Zhaoming $\mathrm{Li}^{2 *}$ \\ ${ }^{1}$ Department of Neurology, The First Affiliated Hospital of Zhengzhou University, Zhengzhou, China, ${ }^{2}$ Department of \\ Oncology, The First Affiliated Hospital of Zhengzhou University, Zhengzhou, China
}

Programmed death receptor 1 (PD-1) or programmed death ligand 1 (PD-L1) blocking therapy has completely changed the treatment pattern of malignant tumors. It has been tested in a wide range of malignant tumors and achieved clinical success. It might be a promising cancer treatment strategy. However, one of the important disadvantages of PD-1/PD-L1 blocking therapy is that only a few patients have a positive response to it. In addition, primary or acquired drug resistance can also lead to cancer recurrence in patients with clinical response. Therefore, it is very important to overcome the resistance of PD-1/PD-L1 blocking therapy and improve the overall response rate of patients to the immunotherapy. T cell immunoglobulin and mucin domain molecule 3 (Tim-3) belongs to the co-inhibitory receptor family involved in immune checkpoint function. Due to adaptive resistance, the expression of Tim-3 is up-regulated in PD-1/PD-L1 blocking therapy resistant tumors. Therefore, blocking the immune checkpoint Tim-3 might antagonize the resistance of PD-1/PD-L1 blocking therapy. This review systematically introduces the preclinical and clinical data of combined blockade of Tim-3 and PD-1/PD-L1 in cancer immunotherapy, and discusses the prospect of overcoming the drug resistance of PD-1/ PD-L1 blockade therapy through blockade of Tim-3.

Keywords: Tim-3, PD-1, PD-L1, immune checkpoint, drug resistance

\section{INTRODUCTION}

Co-inhibitory receptors play the following important roles in cells: regulating $\mathrm{T}$ cell response and maintaining immune homeostasis (1). However, co-inhibitory receptors also limit the ability of T cells to respond effectively to tumors or pathogens. T cells express a variety of co-inhibitory receptors: CTLA-4 (cytotoxic T lymphocyte associated protein 4 or CD152), PD-1 (programmed death ligand 1 or CD279), Tim-3 (T cell immunoglobulin and mucin containing protein 3 or CD366), TIGIT (T cell immune receptor with immunoglobulin and ITIM domains), LAG-3 (lymphocyte activation gene 3 or CD223) and Vista (T cell activation inhibitor containing V domain immunoglobulin) (2-4).

Tim-3 is a type I transmembrane protein which is encoded by gene havcr2 (hepatitis A virus cellular receptor 2) $(5,6)$. Its extracellular domain is composed of the $\mathrm{N}$-terminal immunoglobulin $(\mathrm{IgV})$ domain at the distal end of the membrane, followed by the membrane mucin domain containing O-linked glycosylation potential (7). Tim-3 is expressed in a variety of immune related cells, such as $\mathrm{CD}^{+}$and $\mathrm{CD}^{+} \mathrm{T}$ cells (5), regulatory $\mathrm{T}$ cells (Tregs), natural killer (NK) cells, macrophages, mast cells and dendritic cells (DC) (8-12). 


\section{LIGANDS AND SIGNALING PATHWAYS OF Tim-3}

So far, four ligands have been identified to interact with different regions of Tim-3 extracellular immunoglobulin $\mathrm{V}$ domain: galectin-9 (Gal-9), phosphatidylserine (PtdSer), high-mobility group protein B1 (HMGB1), and cell adhesion molecule bound to carcinoembryonic antigen 1 (CEACAM1) $(2,13)$.

The Tim-3 IgV domain are composed of two anti-parallel $\beta$-sheets with A, G, F, C, C' and C' $\beta$-strands in one sheet (GFC $\beta$-sheet) and the short $\beta$-strands, B, E and D in the other sheet (BED $\beta$-sheet) (Figure 1, right upper panel). It contains six conserved Cys residues, and the first and last of these six Cys residues bridge the $\beta$-sheets. The four additional Cys residues form two additional disulfide bonds that fix the long CC' loop folded upwards onto the GFC $\beta$-sheet. The critical feature of Tim-3 IgV domain is a deep binding pocket flanked by two hydrophobic loops that can extend into a membrane (Figure 1, right lower panel). The tip of the CC' loop projects parallel to the FG loop in the $\operatorname{IgV}$ domain, generating a pocket that is used for recognition of ligands $(6,14)$. The binding of Tim-3 to Gal-9 induces the phosphorylation of two key tyrosine residues, $\mathrm{Y} 265$ and Y272 (Y256 and Y263 in mice), which in turn promotes the release of BAT3 from the cytoplasmic tail of Tim-3 $(15,16)$. After BAT3 release, Src kinase binds and promotes the subsequent negative regulation of T-cell receptor (TCR) signal transduction $(16,17)$. CEACAM1 and Gal-9 bind to different IgV domains, but both ligands induce the phosphorylation of the same two tyrosine residues which are required for the functional activity of Tim-3 (17-25). PtdSer is a non-protein ligand that is shared

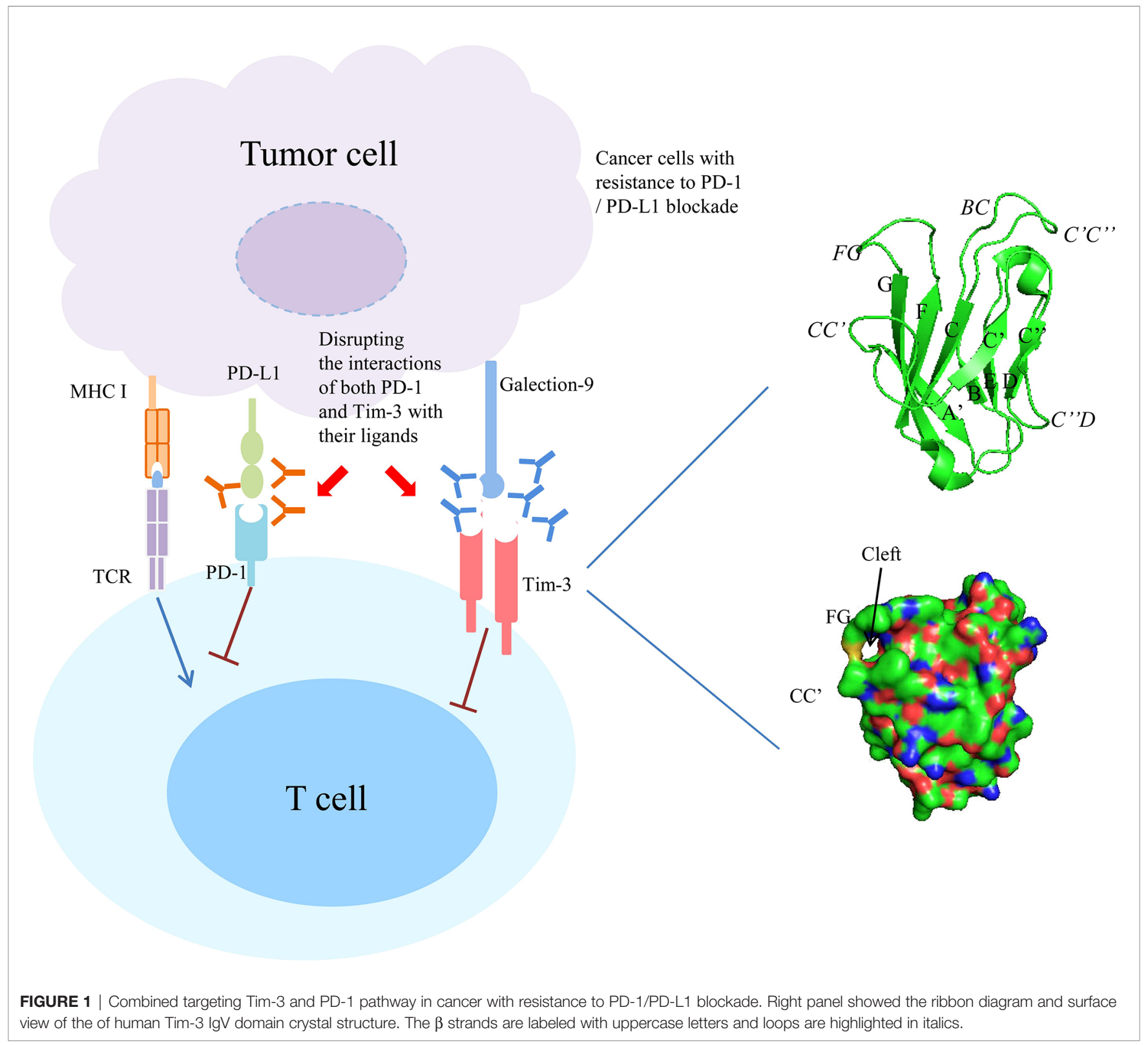


among different Tim family members and released from apoptotic cells $(13,26-28)$. It have been reported that Tim-3 recognizes apoptotic cells through the FG loop in the $\mathrm{IgV}$ domain (Figure 1) (14, 29-34). The last one ligand is HMGB1 $(35,36)$. Binding of Tim-3 with HMGB1 interfered with the recruitment of nucleic acids into DC endosomes, which lead to the attenuated therapeutic efficacy of DNA vaccination and chemotherapy by diminishing the immunogenicity of nucleic acids released from dying cancer cells (35).

\section{Tim-3 EXPRESSION AND ITS ROLE IN REGULATING ANTI-TUMOR IMMUNITY}

Tim-3 was initially identified as expressed on cytotoxic T cells ( $\mathrm{Tc1}$ ) and $\mathrm{T}$ helper type 1 (Th1) cells and acts mainly as a negative regulator of type 1 immunity (5). Tim-3 is also highly expressed in NK cells, macrophages and dendritic cells (37-42). The binding of Gal- 9 on Tim-3 promotes the production of IFN- $\gamma$ by NK cells, while blocking Tim-3 by specific antibody will inhibit IFN- $\gamma$ production (40). Tim-3 expression on macrophages is down regulated in response to TLR4 stimulation and has an inhibitory effect during sepsis (43). In dendritic cells, the binding of Tim-3 to HMGB1 inhibits dendritic cells activation by interfering with the nucleic acid sensing (35).

Increased expression of Tim-3 in human tumors, particularly on immune cells, might be a potential prognostic biomarker for a variety of tumors. For example, in patients with hepatitis B virus related hepatocellular carcinoma (HCC), the expression of Tim3 on $\mathrm{CD}^{+}$and $\mathrm{CD} 8^{+} \mathrm{T}$ cells was increased. Tim $-3^{+} \mathrm{T}$ cells were replicative senescent and expressed surface and genetic markers for senescence (44-46). In addition, the number of tumor infiltrating cells in Tim $-3^{+}$was negatively correlated with the survival rate of HCC patients $(47,48)$. In prostate cancer, the expression of Tim-3 is higher than that of adjacent benign tissues, and the high expression of Tim-3 is an independent predictor of recurrence free and progression free survival (4953). It has been shown that the abnormal expression of Tim-3 in tumor was closely related to the depletion of T cells $(52,54-57)$. For example, in a variety of mouse tumor models, Tim-3 is widely expressed on $\mathrm{CD}^{+}$tumor infiltrating lymphocytes (58). In mice bearing the solid tumor CT26 colon carcinoma, it shows that among CD8+ TILs, cells that coexpress Tim-3 and PD-1 comprise the major population ( $\sim 50 \%)$ with cells expressing PD-1 alone or neither Tim-3 nor PD-1 comprising smaller populations ( $\sim 30 \%$ and $\sim 20 \%$, respectively) (59). This phenomena was also observed in mice bearing two other solid tumors: 4T1 mammary adenocarcinoma and B16F10 melanoma (59). Tim- $3^{+}$PD-1+ tumor infiltrating lymphocytes showed the most severe failure phenotype, which was characterized by the inability to proliferate and produce IFN- $\gamma$, IL-2 and TNF- $\alpha(44,51,58-61)$.

Tim-3 also participates in the progression of tumor by regulating Tim $-3^{+}$Foxp $3^{+}$Treg cells and innate immune cells (62-65). For example, Tim $-3^{+}$Foxp $3^{+} \mathrm{CD}^{+}$cells are widely found in non-small-cell lung carcinoma (NSCLC), HCC, cervical, colorectal and ovarian cancer et al. (66-70). In NSCLC, about $70 \%$ of Tim $-3^{+}$CD $4^{+}$TILs expressed Foxp3, and about $60 \%$ of Foxp $3^{+}$tumor infiltrating lymphocytes were Tim-3 positive $(9,71)$. It is important that the T cells expressed Tim-3 on $\mathrm{CD}^{+}$are associated with lymph node metastasis and advanced cancer staging (62). In patients with HCC, the expression of Tim-3 in peripheral blood mononuclear cells and tumor-associated macrophages (TAM) increased significantly, and that is closely related to higher tumor grade and poor survival for patients with $\operatorname{HCC}(44,72,73)$. In addition, the interference of Tim-3 in macrophages significantly inhibited the alternative activation of macrophages, and inhibited the growth of HCC cells in vitro and in vivo $(44,72,73)$.

In addition, Tim-3 was also directly expressed in tumor cells (62). For example, Tim-3 is expressed in osteosarcoma and triggers tumor cells to obtain aggressive EMT characteristics (62). In clear cell renal cell carcinoma, Tim-3 was expressed on cancer cells and CD204 $4^{+}$tumor related macrophages. The higher expression level of Tim-3 was positively correlated with the short progression free survival (PFS) of patients with clear cell renal cell carcinoma (74). In acute myeloid leukemia (AML), Tim-3 was not expressed on normal hematopoietic stem cells, but mainly on leukemic stem cells in most types of AML (75). Recently, a number of studies have found that the mutation of Tim-3 might be related to the occurrence of subcutaneous panniculitis like T-cell lymphoma (76-79).

\section{RATIONALE FOR TARGETING BOTH PD-1 AND Tim-3}

Cancer immunotherapy with monoclonal antibodies to PD-1 and PD-L1 has achieved significant therapeutic effects in various cancers (80-84). However, it is worth noting that patients who receive anti $\mathrm{PD}-1$ or anti $\mathrm{PD}-\mathrm{L} 1$ monoclonal antibody treatment will confront with the drug resistance problems, which leads to cancer recurrence in many patients (85).

First, in the chronic lymphocytic choriomeningitis virus infection, virus-specific CD8 T cells retained high Tim-3 expression throughout chronic infection. The majority (65\% to $80 \%)$ of lymphocytic choriomeningitis virus-specific CD8 $\mathrm{T}$ cells in lymphoid and nonlymphoid organs coexpressed Tim-3 and PD-1. This coexpression was associated with more severe CD8 T-cell exhaustion in terms of proliferation and secretion of effector cytokines such as IFN-gamma, TNF-alpha, and IL-2. Interestingly, CD8 $\mathrm{T}$ cells expressing both inhibitory receptors also produced the suppressive cytokine IL-10. Most importantly, combined blockade of Tim-3 and PD-1 pathways in vivo synergistically improved CD8 T cell responses and viral control in chronically infected mice. Taken together, it suggests that targeting both PD- 1 and Tim- 3 is an effective immune strategy for treating chronic viral infections.

Second, Anderson et al. found that CD8+ TILs that coexpress Tim-3 and PD-1 not only represent the most abundant TIL population in multiple solid tumors but also represent the most dysfunctional or exhausted population of TILs (59). They treated CT26 tumor-bearing mice with an anti-Tim-3 antibody, antiPD-L1 antibody, anti-Tim-3 plus anti-PD-L1 antibodies, or control immunoglobulins (59). They found that treatment with anti-Tim-3 alone had little or no effect and treatment with anti- 
PD-L1 alone showed a trend toward delayed tumor growth, but this varied between experiments and did not reach statistical significance. However, combined treatment with anti-Tim-3 and anti-PD-L1 resulted in a dramatic reduction in tumor growth, with $50 \%$ of the mice exhibiting complete tumor regression (59). Similarly, a recent study has found that simultaneous targeting of the Tim-3 and PD-1 pathways also rescues CD8+ T cells from exhaustion in a model of chronic infection (85). Together, these findings support combined targeting of the Tim-3 and PD-1 pathways as an effective treatment not only for cancer but also for other chronic immune conditions where $\mathrm{T}$ cell exhaustion is known to occur.

Third, a preclinical investigation evaluated the effects of dual PD-1 and Tim-3 blockade with radiation in human glioblastoma multiforme. C57BL/6 mice were implanted with murine glioma cell line GL261-luc2 and randomized into 8 treatment arms: (i) control, (ii) SRS(stereotactic radiosurgery), (iii) anti-PD-1 antibody, (iv) Tim3 antibody, (v) anti-PD-1 + SRS, (vi) Tim-3 + SRS, (vii) anti-PD-1 + Tim-3, and (viii) anti-PD-1 + Tim-3 + SRS. It showed that neither Tim-3 nor SRS alone had significant treatment effect, whereas antiPD-1 improved median survival (33 days) compared with control (22 days, $\mathrm{P}<0.0001)$. Adding Tim-3 to anti-PD-1 therapy improved median survival from 33 days (anti-PD- 1 alone) to 100 days (Tim-3+ anti-PD-1) and improved overall survival (OS) from $27.8 \%$ to $57.9 \%$, respectively (86). Therefore, combined targeting of the Tim-3 and PD-1 pathways is more effective in suppressing tumor growth than any single target pathway.

Last, another independent study used two genetically engineered mouse models of lung adenocarcinomas corresponding to the two most common oncogene drivers in human lung adenocarcinoma, KRAS and EGFR. The EGFR and Kras models were treated with a therapeutic anti-PD-1 antibody until tumors demonstrated progression by magnetic resonance imaging and evaluated immune profiles. It found that upregulation of other immune checkpoints, most notably Tim-3, on therapeutic antibody-bound $\mathrm{T}$ cells as a marker of treatment resistance. To determine whether blockade of Tim-3 at the time of resistance might be therapeutically efficacious, TIM-3-blocking treatment in these mice were performed and demonstrated a clinical benefit. Moreover, to extend these results and determine their applicability to patients treated with anti-PD-1 antibodies, specimens from two patients who showed an initial response to PD-1 blockade but ultimately developed progressive disease were analyzed. These cases exhibited similar upregulation of Tim-3 on therapeutic antibody-bound TILs. These results suggest that targeting alternate immune checkpoints such as Tim-3 upregulated in the context of PD-1 therapy may extend the benefit of $\mathrm{PD}-1$ blockade in responsive tumors (87) (Figure 1).

\section{CLINICAL TRIALS OF TARGETING BOTH PD-1 AND Tim-3 IN HUMAN TUMORS}

At present, there are several ongoing clinical trials to explore the application of combined blocking Tim-3 and PD-1 in advanced solid tumors (Table $\mathbf{1}$ ).
A phase I/II study evaluated the safety and efficacy of sabatomimab with or without spartalizumab in patients with advanced solid tumors (88). Among 219 patients, the most common were ovarian cancer (17\%) and colorectal cancer (7\%). 133 patients were treated with sabatolimab, 86 patients were treated with sabatomimab combined with spartalizumab. The most common adverse event suspected to be treatment-related was fatigue (9\%, sabatolimab; $15 \%$, combination). No responses were seen with sabatolimab. Five patients receiving combination treatment had partial responses (6\%; lasting 12-27 months) in colorectal cancer $(n=2)$, non-small cell lung cancer (NSCLC), malignant perianal melanoma, and SCLC. Of the five, two patients had elevated expression of immune markers in baseline biopsies; another three had $>10 \%$ TIM-3-positive staining, including one patient with NSCLC who received prior PD-1 therapy (88). It suggested that sabatomimab combined with spartalizumab was well tolerated and showed preliminary signs of antitumor activity.

LY3321367 is a novel Tim-3 monoclonal antibody. An open label, multicenter, phase Ia/b solid tumor study explored the safety, tolerability, recommended phase II dose, pharmacokinetics/ pharmacodynamics, immunogenicity and efficacy of LY3321367 alone or in combination with anti-PD-L1 antibody LY300054 (89). No dose limiting toxicity was observed in the dose escalation of monotherapy $(n=30)$ or combination therapy $(n=28)$. The treatment-related adverse events of LY3321367 ( $\geq 2$ patients) mainly included pruritus, fatigue, rash, anorexia and infusion related reactions. In the non-small cell lung cancer monotherapy expansion cohort, outcomes varied by prior anti-PD-1 therapy response status: anti-PD-1/L1 refractory patients $(\mathrm{m}=23$, objective response rate (ORR) 0\%, disease control rate (DCR) 35\%, progression-free survival (PFS) 1.9 months) versus anti-PD-1/L1 responders ( $\mathrm{n}=14$, ORR 7\%, DCR 50\%, PFS 7.3 months). In combination expansion cohorts $(n=91)$, ORR and DCR were $4 \%$ and 42\% (89). LY3321367 showed acceptable safety and good pharmacokinetics/pharmacodynamics, but its anti-tumor activity needs further study. Besides, this study has limitations. The small sample size and the unselected enrollment of patients might result in statistical bias and limit the statistical power of this study to some degree.

LY3415244 is a bispecific antibody against Tim-3/PD-L1. A phase I, multicenter, open label study evaluated the safety and efficacy of combined blockade of Tim-3 and PD-L1 in patients with advanced solid tumors (90). A total of 12 patients were included in this study and received at least one dose of LY3415244. Two patients (16.7\%) developed clinically significant anaphylactic infusionrelated reactions and all patients developed treatment-emergent antidrug antibodies (TE-ADA). ADA titers were sometimes very high and negatively impacted soluble TIM-3 target engagement in most patients. ADA epitope specificity was against both TIM- 3 and PD-L1 arms of the bispecific antibody (90). This TIM-3 and PD-L1 bispecific format was associated with unexpected immunogenicity targeting both arms of the bispecific antibody, which might be responsible for the early study termination. Therefore, this experience emphasizes the importance of thorough analyses for preexisting $\mathrm{ADAs}$ as part of immunogenicity risk assessment of novel antibodies. 
TABLE 1 | Main ongoing clinical trials of anti-Tim-3 combined with anti-PD-1 antibody.

\begin{tabular}{|c|c|c|c|c|}
\hline NCT Number & Title & Tumor type & Interventions & Phases \\
\hline NCT04931654 & $\begin{array}{l}\text { A Study to Assess the Safety and Efficacy of AZD7789 in Participants With Advanced or } \\
\text { Metastatic Solid Cancer }\end{array}$ & $\begin{array}{l}\text { Non-Small-Cell } \\
\text { Lung cancer }\end{array}$ & Drug: AZD7789 & Phase $1 / / 1$ \\
\hline NCT04370704 & $\begin{array}{l}\text { Study of Combination Therapy With INCMGA00012, INCAGN02385, and INCAGN02390 } \\
\text { in Participants With Select Advanced Malignancies }\end{array}$ & Melanoma & $\begin{array}{l}\text { Drug: INCAGN02385| } \\
\text { Drug: INCAGN02390| } \\
\text { Drug: INCMGA00012. }\end{array}$ & Phase $1 / 11$ \\
\hline NCT03961971 & Trial of Tim-3 in Combination With anti-PD-1 and SRS in Recurrent GBM & $\begin{array}{l}\text { Glioblastoma } \\
\text { Multiforme }\end{array}$ & Drug: sabatomimab & Phase I \\
\hline NCT03744468 & Study of BGB-A425 in Combination With Tislelizumab in Advanced Solid Tumors & Solid Tumors & $\begin{array}{l}\text { Drug: BGB-A425|Drug: } \\
\text { tislelizumab }\end{array}$ & Phase $1 / 11$ \\
\hline NCT04641871 & $\begin{array}{l}\text { Sym021 in Combination With Either Sym022 or Sym023 in Patients With Advanced Solid } \\
\text { Tumor Malignancies }\end{array}$ & Solid Tumors & $\begin{array}{l}\text { Drug: Sym021|Drug: } \\
\text { Sym022|Drug: Sym023 }\end{array}$ & Phase I \\
\hline NCT04785820 & $\begin{array}{l}\text { A Study of RO7121661 and RO7247669 Compared With Nivolumab in Participants With } \\
\text { Advanced or Metastatic Squamous Cell Carcinoma of the Esophagus }\end{array}$ & $\begin{array}{l}\text { Esophageal } \\
\text { Squamous Cell } \\
\text { Carcinoma }\end{array}$ & $\begin{array}{l}\text { Drug: RO7121661|Drug: } \\
\text { RO7247669|Drug: } \\
\text { Nivolumab }\end{array}$ & Phase II \\
\hline NCT02817633 & A Study of TSR-022 in Participants With Advanced Solid Tumors (AMBER) & Solid Tumors & Drug: TSR-022,Nivolumab & Phase I \\
\hline NCT02608268 & $\begin{array}{l}\text { Phase I-Ib/II Study of sabatomimab as Single Agent and in Combination With PDR001 in } \\
\text { Patients With Advanced Malignancies }\end{array}$ & $\begin{array}{l}\text { Advanced } \\
\text { Malignancies }\end{array}$ & $\begin{array}{l}\text { Drug: Sabatomimab|Drug: } \\
\text { PDR001|Drug: Decitabine }\end{array}$ & Phase I/II \\
\hline
\end{tabular}

TSR-022, Tim-3 antibody; TSR-042, anti-PD-1 antibody; RO7121661, PD1-Tim-3 bispecific antibody; RO7247669, PD1-LAG3 bispecific antibody; AZD7789, anti-PD-1 and Tim-3 bispecific antibody; INCMGA00012, anti-PD-1 antibody; INCAGNO2385, anti-LAG-3 antibody; INCAGNO2390, Tim-3 antibody; BGB-A425, humanized immunoglobulin gamma-1 (IgG1)variant monoclonal antibody against Tim-3; Tislelizumab, humanized immunoglobulin G4 (IgG4)-variant monoclonal antibody against PD-1; TSR-022, Tim-3 antibody; Sabatomimab, Tim-3 antibody.

In addition, sabatomimab and spartalizumab are humanized IgG4 monoclonal antibodies. Sabatomimab blocks the binding of Tim-3 to PtdSer, while spartalizumab blocks the binding of PD-1 to PD-L1/2. A phase II clinical trial (NCT02608268) explored the dose expansion of sabatomimab combined with spartalizumab in patients with NSCLC and melanoma. Thirty three patients received combination therapy, including 16 patients with melanoma and 17 patients with NSCLC. The preliminary results showed that sabatomimab combined with spartalizumab was well tolerated, but the efficacy of combination of sabatomimab and spartalizumab in patients with melanoma and NSCLC needs further data (91).

\section{CONCLUSION AND PERSPECTIVES}

The activation of naive $\mathrm{T}$ cells requires both the stimulation of the TCR by MHC-peptide complex and co-stimulatory signaling by co-stimulatory receptors with their corresponding ligands on antigen-presenting cells (92-95). There are stimulatory and inhibitory co-receptors on the cell-surface which positively or negatively regulate TCR driven signals, respectively (95). To date, many co-stimulatory receptors have been identified including CD28, ICOS, 4-1BB, CD226, OX-40, and GITR (95). For example, the co-stimulatory receptor $\mathrm{CD} 28$ on $\mathrm{T}$ cells and its ligand B7-1 or B7-2 on activated APCs amplify TCR signaling, leading to T-cell proliferation and IL-2 production $(95,96)$. When $\mathrm{T}$ cells are being activated and expanded, the expression of co-inhibitory receptors is up-regulated. Co-inhibitory receptors includes PD-1, CTLA-4, TIM-3, LAG-3, and TIGIT (95). They play an important role in activated $\mathrm{T}$ cells, regulatory $\mathrm{T}$ cells, and exhausted $\mathrm{T}$ cells. These receptors suppress $\mathrm{T}$-cell function in the tumor microenvironment, thereby making the $\mathrm{T}$ cells dysfunctional. Therefore, blockade of co-inhibitory receptors (such as PD-1) has emerged as a successful treatment option for a number of human cancers (97). However, primary or acquired drug resistance may eventually lead to cancer progression in patients with clinical response (3). Therefore, resistance to PD-1/PD-L1 blockade remains a major challenge to its further application. Accumulating evidence supports the importance of targeting Tim-3 in the treatment of cancer. Importantly, a number of preclinical studies have shown that, compared with the use of anti-PD-1 antibody alone, the combined treatment of blocking Tim-3 and PD-1 can significantly improve the survival rate of mice $(59,87)$. Moreover, several ongoing clinical trials have also evaluated the safety and efficacy of the combination therapy (88, 89). Therefore, the combined blockade of Tim- 3 and PD-1 pathway might be a promising strategy for tumor immunotherapy. 
Although a number of preclinical and clinical studies have shown that, compared with the use of anti-PD-1 antibody alone, the combined treatment of blocking Tim-3 and PD-1 might be a better strategy for tumor immunotherapy, there are still more challenges and questions to be answered. First, there is a lack of valid biomarkers which can predict successful treatment with this combination currently. Recently studies showed that the even expression level of PD-L1 does not necessarily predict successful treatment $(31,98)$. Therefore, this combination should be approved on the basis of these biomarkers to limit ineffective treatments in the future. Next generation sequencing and nanostring analysis showing the results of total mutational burden or certain immune signatures present promising tests with the potential to discriminate between immune responsive or unresponsive patients, thus requiring further studies to confirm their utility as a predictive marker. Second, combinations will have to be patient tailored since they are likely to be more toxic than single agents and more expensive. Third, cells usually have functionally redundant pathways which could override and compensate for each other. Exhausted T cells upregulate several exhaustion markers (LAG-3,TIGIT and Tim-3 et al)

\section{REFERENCES}

1. Waterhouse P, Penninger JM, Timms E, Wakeham A, Shahinian A, Lee KP, et al. Lymphoproliferative Disorders With Early Lethality in Mice Deficient in Ctla-4. Science (1995) 270(5238):985-8. doi: 10.1126/science.270.5238.985

2. Joller N, Kuchroo VK. Tim-3, Lag-3, and TIGIT. Curr Topics Microbiol Immunol (2017) 410:127-56. doi: 10.1007/82_2017_62

3. Wherry EJ, Kurachi M. Molecular and Cellular Insights Into T Cell Exhaustion. Nat Rev Immunol (2015) 15(8):486-99. doi: 10.1038/nri3862

4. Linsley PS, Brady W, Urnes M, Grosmaire LS, Damle NK, Ledbetter JA. CTLA-4 is a Second Receptor for the B Cell Activation Antigen B7. J Exp Med (1991) 174(3):561-9. doi: 10.1084/jem.174.3.561

5. Monney L, Sabatos CA, Gaglia JL, Ryu A, Waldner H, Chernova T, et al. Th1Specific Cell Surface Protein Tim-3 Regulates Macrophage Activation and Severity of an Autoimmune Disease. Nature (2002) 415(6871):536-41. doi: $10.1038 / 415536 \mathrm{a}$

6. Freeman GJ, Casasnovas JM, Umetsu DT, DeKruyff RH. TIM Genes: A Family of Cell Surface Phosphatidylserine Receptors That Regulate Innate and Adaptive Immunity. Immunol Rev (2010) 235(1):172-89. doi: 10.1111/ j.0105-2896.2010.00903.x

7. Meyers JH, Sabatos CA, Chakravarti S, Kuchroo VK. The TIM Gene Family Regulates Autoimmune and Allergic Diseases. Trends Mol Med (2005) 11 (8):362-9. doi: 10.1016/j.molmed.2005.06.008

8. Anderson AC, Lord GM, Dardalhon V, Lee DH, Sabatos-Peyton CA, Glimcher LH, et al. T-Bet, a Th1 Transcription Factor Regulates the Expression of Tim-3. Eur J Immunol (2010) 40(3):859-66. doi: 10.1002/ eji.200939842

9. Gao X, Zhu Y, Li G, Huang H, Zhang G, Wang F, et al. TIM-3 Expression Characterizes Regulatory T Cells in Tumor Tissues and Is Associated With Lung Cancer Progression. PloS One (2012) 7(2):e30676. doi: 10.1371/ journal.pone.0030676

10. Ndhlovu LC, Lopez-Verges S, Barbour JD, Jones RB, Jha AR, Long BR, et al. Tim-3 Marks Human Natural Killer Cell Maturation and Suppresses CellMediated Cytotoxicity. Blood (2012) 119(16):3734-43. doi: 10.1182/blood2011-11-392951

11. Gao L, Yu S, Zhang X. Hypothesis: Tim-3/Galectin-9, a New Pathway for Leukemia Stem Cells Survival by Promoting Expansion of Myeloid-Derived Suppressor Cells and Differentiating Into Tumor-Associated Macrophages. Cell Biochem Biophys (2014) 70(1):273-7. doi: 10.1007/s12013-014-9900-0 and that targeting one of these will simply lead to an overexpression of another. The combination strategies should be carefully designed and should take into account $\mathrm{T}$ cell activation or exhaustion status. Notably, as compared to the two other immune checkpoints LAG-3 and TIGIT, Tim-3 is less validated and more robust clinical trials are still needed.

\section{AUTHOR CONTRIBUTIONS}

TT and ZL contributed to the conception of the study and wrote the manuscript. All authors contributed to the article and approved the submitted version.

\section{FUNDING}

This study was supported by National natural Science Foundation of China (U1904139, 82070209 and U1804171), Department of Science \& Technology of Henan province (182102310114).

12. Phong BL, Avery L, Sumpter TL, Gorman JV, Watkins SC, Colgan JD, et al. Tim-3 Enhances FcepsilonRI-Proximal Signaling to Modulate Mast Cell Activation. J Exp Med (2015) 212(13):2289-304. doi: 10.1084/jem.20150388

13. Wang Z, Chen J, Wang M, Zhang L, Yu L. One Stone, Two Birds: The Roles of Tim-3 in Acute Myeloid Leukemia. Front Immunol (2021) 12:618710. doi: $10.3389 /$ fimmu.2021.618710

14. Gandhi AK, Kim WM, Sun ZJ, Huang YH, Bonsor DA, Sundberg EJ, et al. High Resolution X-Ray and NMR Structural Study of Human T-Cell Immunoglobulin and Mucin Domain Containing Protein-3. Sci Rep (2018) 8(1):17512. doi: 10.1038/s41598-018-35754-0

15. Zhu C, Anderson AC, Schubart A, Xiong H, Imitola J, Khoury SJ, et al. The Tim-3 Ligand Galectin-9 Negatively Regulates T Helper Type 1 Immunity. Nat Immunol (2005) 6(12):1245-52. doi: 10.1038/ni1271

16. Rangachari M, Zhu C, Sakuishi K, Xiao S, Karman J, Chen A, et al. Bat3 Promotes $\mathrm{T}$ Cell Responses and Autoimmunity by Repressing Tim-3Mediated Cell Death and Exhaustion. Nat Med (2012) 18(9):1394-400. doi: 10.1038/nm.2871

17. Huang YH, Zhu C, Kondo Y, Anderson AC, Gandhi A, Russell A, et al. CEACAM1 Regulates TIM-3-Mediated Tolerance and Exhaustion. Nature (2015) 517(7534):386-90. doi: 10.1038/nature13848

18. Sabatos-Peyton CA, Nevin J, Brock A, Venable JD, Tan DJ, Kassam N, et al. Blockade of Tim-3 Binding to Phosphatidylserine and CEACAM1 Is a Shared Feature of Anti-Tim-3 Antibodies That Have Functional Efficacy. Oncoimmunology (2018) 7(2):e1385690. doi: 10.1080/2162402X.2017.1385690

19. Dankner M, Gray-Owen SD, Huang YH, Blumberg RS, Beauchemin N. CEACAM1 as a Multi-Purpose Target for Cancer Immunotherapy. Oncoimmunology (2017) 6(7):e1328336. doi: 10.1080/2162402X.2017.1328336

20. Kim WM, Huang YH, Gandhi A, Blumberg RS. CEACAM1 Structure and Function in Immunity and Its Therapeutic Implications. Semin Immunol (2019) 42:101296. doi: 10.1016/j.smim.2019.101296

21. Zhang Y, Cai P, Li L, Shi L, Chang P, Liang T, et al. Co-Expression of TIM-3 and CEACAM1 Promotes T Cell Exhaustion in Colorectal Cancer Patients. Int Immunopharmacol (2017) 43:210-8. doi: 10.1016/j.intimp.2016.12.024

22. Nagaishi T, Iijima $H$, Nakajima A, Chen D, Blumberg RS. Role of CEACAM1 as a Regulator of T Cells. Ann New York Acad Sci (2006) 1072:155-75. doi: 10.1196/annals.1326.004

23. De Sousa Linhares A, Kellner F, Jutz S, Zlabinger GJ, Gabius HJ, Huppa JB, et al. TIM-3 and CEACAM1 do Not Interact in Cis and in Trans. Eur J Immunol (2020) 50(8):1126-41. doi: 10.1002/eji.201948400 
24. Cheng L, Ruan Z. Tim-3 and Tim-4 as the Potential Targets for Antitumor Therapy. Hum Vaccines Immunotherapeutics (2015) 11(10):2458-62. doi: 10.1080/21645515.2015.1056953

25. Lake CM, Voss K, Bauman BM, Pohida K, Jiang T, Dveksler G, et al. TIM-3 Drives Temporal Differences in Restimulation-Induced Cell Death Sensitivity in Effector CD8(+) T Cells in Conjunction With CEACAM1. Cell Death Dis (2021) 12(4):400. doi: 10.1038/s41419-021-03689-6

26. Du W, Yang M, Turner A, Xu C, Ferris RL, Huang J, et al. TIM-3 as a Target for Cancer Immunotherapy and Mechanisms of Action. Int J Mol Sci (2017) 18(3):645. doi: 10.3390/ijms18030645

27. Kuang Z, Li L, Zhang P, Chen B, Wu M, Ni H, et al. A Novel Antibody Targeting TIM-3 Resulting in Receptor Internalization for Cancer Immunotherapy. Antibody Ther (2020) 3(4):227-36. doi: 10.1093/abt/tbaa022

28. Perez-Lara A, Thapa A, Nyenhuis SB, Nyenhuis DA, Halder P, Tietzel M, et al. PtdInsP2 and PtdSer Cooperate to Trap Synaptotagmin-1 to the Plasma Membrane in the Presence of Calcium. eLife (2016) 5:e15886. doi: 10.7554/ eLife. 15886

29. Cao E, Zang X, Ramagopal UA, Mukhopadhaya A, Fedorov A, Fedorov E, et al. T Cell Immunoglobulin Mucin-3 Crystal Structure Reveals a Galectin-9Independent Ligand-Binding Surface. Immunity (2007) 26(3):311-21. doi: 10.1016/j.immuni.2007.01.016

30. Nakayama M, Akiba H, Takeda K, Kojima Y, Hashiguchi M, Azuma M, et al. Tim-3 Mediates Phagocytosis of Apoptotic Cells and Cross-Presentation. Blood (2009) 113(16):3821-30. doi: 10.1182/blood-2008-10-185884

31. Kok VC. Current Understanding of the Mechanisms Underlying Immune Evasion From PD-1/PD-L1 Immune Checkpoint Blockade in Head and Neck Cancer. Front Oncol (2020) 10:268. doi: 10.3389/fonc.2020.00268

32. DeKruyff RH, Bu X, Ballesteros A, Santiago C, Chim YL, Lee HH, et al. T Cell/ Transmembrane, Ig, and Mucin-3 Allelic Variants Differentially Recognize Phosphatidylserine and Mediate Phagocytosis of Apoptotic Cells. J Immunol (2010) 184(4):1918-30. doi: 10.4049/jimmunol.0903059

33. Anderson AC, Xiao S, Kuchroo VK. Tim Protein Structures Reveal a Unique Face for Ligand Binding. Immunity (2007) 26(3):273-5. doi: 10.1016/ j.immuni.2007.03.004

34. Kikushige Y. TIM-3 in Normal and Malignant Hematopoiesis: Structure, Function and Signaling Pathways. Cancer Sci (2021) 112(9):3419-26. doi: $10.1111 /$ cas. 15042

35. Chiba S, Baghdadi M, Akiba H, Yoshiyama H, Kinoshita I, Dosaka-Akita H, et al. Tumor-Infiltrating DCs Suppress Nucleic Acid-Mediated Innate Immune Responses Through Interactions Between the Receptor TIM-3 and the Alarmin HMGB1. Nat Immunol (2012) 13(9):832-42. doi: 10.1038/ ni. 2376

36. Tang D, Lotze MT. Tumor Immunity Times Out: TIM-3 and HMGB1. Nat Immunol (2012) 13(9):808-10. doi: 10.1038/ni.2396

37. Datar I, Sanmamed MF, Wang J, Henick BS, Choi J, Badri T, et al. Expression Analysis and Significance of PD-1, LAG-3, and TIM-3 in Human Non-Small Cell Lung Cancer Using Spatially Resolved and Multiparametric Single-Cell Analysis. Clin Cancer Res an Off J Am Assoc Cancer Res (2019) 25(15):466373. doi: 10.1158/1078-0432.CCR-18-4142

38. So EC, Khaladj-Ghom A, Ji Y, Amin J, Song Y, Burch E, et al. NK Cell Expression of Tim-3: First Impressions Matter. Immunobiology (2019) 224 (3):362-70. doi: 10.1016/j.imbio.2019.03.001

39. Yong YK, Saeidi A, Tan HY, Rosmawati M, Enstrom PF, Batran RA, et al. Hyper-Expression of PD-1 Is Associated With the Levels of Exhausted and Dysfunctional Phenotypes of Circulating CD161(++)TCR Ivalpha7.2(+) Mucosal-Associated Invariant T Cells in Chronic Hepatitis B Virus Infection. Front Immunol (2018) 9:472. doi: 10.3389/fimmu.2018.00472

40. Gleason MK, Lenvik TR, McCullar V, Felices M, O'Brien MS, Cooley SA, et al. Tim-3 Is an Inducible Human Natural Killer Cell Receptor That Enhances Interferon Gamma Production in Response to Galectin-9. Blood (2012) 119 (13):3064-72. doi: 10.1182/blood-2011-06-360321

41. Li Y, Zhang J, Zhang D, Hong X, Tao Y, Wang S, et al. Tim-3 Signaling in Peripheral NK Cells Promotes Maternal-Fetal Immune Tolerance and Alleviates Pregnancy Loss. Sci Signaling (2017) 10(498):eaah4323. doi: 10.1126/scisignal.aah4323

42. Burugu S, Dancsok AR, Nielsen TO. Emerging Targets in Cancer Immunotherapy. Semin Cancer Biol (2018) 52(Pt 2):39-52. doi: 10.1016/ j.semcancer.2017.10.001
43. Yang X, Jiang X, Chen G, Xiao Y, Geng S, Kang C, et al. T Cell Ig Mucin-3 Promotes Homeostasis of Sepsis by Negatively Regulating the TLR Response. J Immunol (2013) 190(5):2068-79. doi: 10.4049/jimmunol.1202661

44. Li H, Wu K, Tao K, Chen L, Zheng Q, Lu X, et al. Tim-3/Galectin-9 Signaling Pathway Mediates T-Cell Dysfunction and Predicts Poor Prognosis in Patients With Hepatitis B Virus-Associated Hepatocellular Carcinoma. Hepatology (2012) 56(4):1342-51. doi: 10.1002/hep.25777

45. Ganjalikhani Hakemi M, Jafarinia M, Azizi M, Rezaeepoor M, Isayev O, Bazhin AV. The Role of TIM-3 in Hepatocellular Carcinoma: A Promising Target for Immunotherapy? Front Oncol (2020) 10:601661. doi: 10.3389/ fonc. 2020.601661

46. Song B, Zhen S, Meng F. T Cell Inflammation Profile After Surgical Resection may Predict Tumor Recurrence in HBV-Related Hepatocellular Carcinoma. Int Immunopharmacol (2016) 41:35-41. doi: 10.1016/j.intimp.2016.10.015

47. Liu F, Liu Y, Chen Z. Tim-3 Expression and Its Role in Hepatocellular Carcinoma. J Hematol Oncol (2018) 11(1):126. doi: 10.1186/s13045-018-0667-4

48. Shrestha R, Prithviraj P, Anaka M, Bridle KR, Crawford DHG, Dhungel B, et al. Monitoring Immune Checkpoint Regulators as Predictive Biomarkers in Hepatocellular Carcinoma. Front Oncol (2018) 8:269. doi: 10.3389/ fonc. 2018.00269

49. Zhang X, Chen H, Li G, Zhou X, Shi Y, Zou F, et al. Increased Tim-3 Expression on TILs During Treatment With the Anchored GM-CSF Vaccine and Anti-PD-1 Antibodies is Inversely Correlated With Response in Prostate Cancer. J Cancer (2020) 11(3):648-56. doi: 10.7150/jca.29705

50. Wu J, Lin G, Zhu Y, Zhang H, Shi G, Shen Y, et al. Low TIM3 Expression Indicates Poor Prognosis of Metastatic Prostate Cancer and Acts as an Independent Predictor of Castration Resistant Status. Sci Rep (2017) 7 (1):8869. doi: 10.1038/s41598-017-09484-8

51. Japp AS, Kursunel MA, Meier S, Malzer JN, Li X, Rahman NA, et al. Dysfunction of PSA-Specific CD8+ T Cells in Prostate Cancer Patients Correlates With CD38 and Tim-3 Expression. Cancer immunol immunother CII (2015) 64(11):1487-94. doi: 10.1007/s00262-015-1752-y

52. Piao YR, Piao LZ, Zhu LH, Jin ZH, Dong XZ. Prognostic Value of T Cell Immunoglobulin Mucin-3 in Prostate Cancer. Asian Pacific J Cancer Prev APJCP (2013) 14(6):3897-901. doi: 10.7314/APJCP.2013.14.6.3897

53. Jochems C, Tucker JA, Tsang KY, Madan RA, Dahut WL, Liewehr DJ, et al. A Combination Trial of Vaccine Plus Ipilimumab in Metastatic Castration-Resistant Prostate Cancer Patients: Immune Correlates. Cancer Immunol Immunother CII (2014) 63(4):407-18. doi: 10.1007/s00262-0141524-0

54. Yuan J, Jiang B, Zhao H, Huang Q. Prognostic Implication of TIM-3 in Clear Cell Renal Cell Carcinoma. Neoplasma (2014) 61(1):35-40. doi: 10.4149/ neo 2014_006

55. Zhou E, Huang Q, Wang J, Fang C, Yang L, Zhu M, et al. Up-Regulation of Tim-3 is Associated With Poor Prognosis of Patients With Colon Cancer. Int J Clin Exp Pathol (2015) 8(7):8018-27.

56. Yang M, Yu Q, Liu J, Fu W, Cao Y, Yu L, et al. T-Cell Immunoglobulin Mucin-3 Expression in Bladder Urothelial Carcinoma: Clinicopathologic Correlations and Association With Survival. J Surg Oncol (2015) 112 (4):430-5. doi: $10.1002 /$ jso.24012

57. Cao Y, Zhou X, Huang X, Li Q, Gao L, Jiang L, et al. Tim-3 Expression in Cervical Cancer Promotes Tumor Metastasis. PloS One (2013) 8(1):e53834. doi: 10.1371/journal.pone.0053834

58. Fourcade J, Sun Z, Benallaoua M, Guillaume P, Luescher IF, Sander C, et al. Upregulation of Tim-3 and PD-1 Expression Is Associated With Tumor Antigen-Specific CD8+ T Cell Dysfunction in Melanoma Patients. J Exp Med (2010) 207(10):2175-86. doi: 10.1084/jem.20100637

59. Sakuishi K, Apetoh L, Sullivan JM, Blazar BR, Kuchroo VK, Anderson AC. Targeting Tim-3 and PD-1 Pathways to Reverse T Cell Exhaustion and Restore Anti-Tumor Immunity. J Exp Med (2010) 207(10):2187-94. doi: 10.1084 /jem.20100643

60. Gupta S, Thornley TB, Gao W, Larocca R, Turka LA, Kuchroo VK, et al. Allograft Rejection is Restrained by Short-Lived TIM-3+PD-1+Foxp3+ Tregs. J Clin Invest (2012) 122(7):2395-404. doi: 10.1172/JCI45138

61. Sakuishi K, Ngiow SF, Sullivan JM, Teng MW, Kuchroo VK, Smyth MJ, et al TIM3(+)FOXP3(+) Regulatory T Cells Are Tissue-Specific Promoters of TCell Dysfunction in Cancer. Oncoimmunology (2013) 2(4):e23849. doi: $10.4161 /$ onci.23849 
62. Das M, Zhu C, Kuchroo VK. Tim-3 and its Role in Regulating Anti-Tumor Immunity. Immunol Rev (2017) 276(1):97-111. doi: 10.1111/imr.12520

63. Zhong W, Liu X, Zhu Z, Li Q, Li K. High Levels of Tim-3(+)Foxp3(+)Treg Cells in the Tumor Microenvironment Is a Prognostic Indicator of Poor Survival of Diffuse Large B Cell Lymphoma Patients. Int Immunopharmacol (2021) 96:107662. doi: 10.1016/j.intimp.2021.107662

64. Dehghani M, Shokrgozar N, Ramzi M, Kalani M, Golmoghaddam H, Arandi $\mathrm{N}$. The Impact of Selenium on Regulatory T Cell Frequency and Immune Checkpoint Receptor Expression in Patients With Diffuse Large B Cell Lymphoma (DLBCL). Cancer Immunol Immunother CII (2021) 70 (10):2961-9. doi: 10.1007/s00262-021-02889-5

65. Toor SM, Murshed K, Al-Dhaheri M, Khawar M, Abu Nada M, Elkord E. Immune Checkpoints in Circulating and Tumor-Infiltrating CD4(+) T Cell Subsets in Colorectal Cancer Patients. Front Immunol (2019) 10:2936. doi: 10.3389/fimmu.2019.02936

66. Langhans B, Nischalke HD, Kramer B, Dold L, Lutz P, Mohr R, et al. Role of Regulatory T Cells and Checkpoint Inhibition in Hepatocellular Carcinoma. Cancer Immunol Immunother CII (2019) 68(12):2055-66. doi: 10.1007/ s00262-019-02427-4

67. Olguin JE, Medina-Andrade I, Molina E, Vazquez A, Pacheco-Fernandez T, Saavedra R, et al. Early and Partial Reduction in CD4(+)Foxp3(+) Regulatory T Cells During Colitis-Associated Colon Cancer Induces CD4(+) and CD8(+) T Cell Activation Inhibiting Tumorigenesis. J Cancer (2018) 9(2):239-49. doi: $10.7150 /$ jca. 21336

68. Gautron AS, Dominguez-Villar M, de Marcken M, Hafler DA. Enhanced Suppressor Function of TIM-3+ FoxP3+ Regulatory T Cells. Eur J Immunol (2014) 44(9):2703-11. doi: 10.1002/eji.201344392

69. Jie HB, Gildener-Leapman N, Li J, Srivastava RM, Gibson SP, Whiteside TL, et al. Intratumoral Regulatory $\mathrm{T}$ Cells Upregulate Immunosuppressive Molecules in Head and Neck Cancer Patients. Br J Cancer (2013) 109 (10):2629-35. doi: 10.1038/bjc.2013.645

70. Guo Z, Cheng D, Xia Z, Luan M, Wu L, Wang G, et al. Combined TIM-3 Blockade and CD137 Activation Affords the Long-Term Protection in a Murine Model of Ovarian Cancer. J Trans Med (2013) 11:215. doi: 10.1186/ 1479-5876-11-215

71. Yang R, Sun L, Li CF, Wang YH, Yao J, Li H, et al. Galectin-9 Interacts With PD-1 and TIM-3 to Regulate T Cell Death and Is a Target for Cancer Immunotherapy. Nat Commun (2021) 12(1):832. doi: 10.1038/s41467-021-21099-2

72. Flecken T, Sarobe P. Tim-3 Expression in Tumour-Associated Macrophages: A New Player in HCC Progression. Gut (2015) 64(10):1502-3. doi: 10.1136/ gutjnl-2014-309094

73. Yan W, Liu X, Ma H, Zhang H, Song X, Gao L, et al. Tim-3 Fosters HCC Development by Enhancing TGF-Beta-Mediated Alternative Activation of Macrophages. Gut (2015) 64(10):1593-604. doi: 10.1136/gutjnl-2014-307671

74. Komohara Y, Morita T, Annan DA, Horlad H, Ohnishi K, Yamada S, et al. The Coordinated Actions of TIM-3 on Cancer and Myeloid Cells in the Regulation of Tumorigenicity and Clinical Prognosis in Clear Cell Renal Cell Carcinomas. Cancer Immunol Res (2015) 3(9):999-1007. doi: 10.1158/23266066.CIR-14-0156

75. Kikushige Y, Shima T, Takayanagi S, Urata S, Miyamoto T, Iwasaki H, et al. TIM-3 Is a Promising Target to Selectively Kill Acute Myeloid Leukemia Stem Cells. Cell Stem Cell (2010) 7(6):708-17. doi: 10.1016/j.stem.2010.11.014

76. Chaweephisal P, Sosothikul D, Polprasert C, Wananukul S, Seksarn P. Subcutaneous Panniculitis-Like T-Cell Lymphoma With Hemophagocytic Lymphohistiocytosis Syndrome in Children and Its Essential Role of HAVCR2 Gene Mutation Analysis. J Pediatr Hematol/Oncol (2021) 43(1): e80-e4. doi: 10.1097/MPH.0000000000001954

77. Sonigo G, Battistella M, Beylot-Barry M, Ingen-Housz-Oro S, Franck N, Barete S, et al. HAVCR2 Mutations are Associated With Severe Hemophagocytic Syndrome in Subcutaneous Panniculitis-Like T-Cell Lymphoma. Blood (2020) 135(13):1058-61. doi: 10.1182/blood.2019003811

78. Gayden T, Sepulveda FE, Khuong-Quang DA, Pratt J, Valera ET, Garrigue A, et al. Germline HAVCR2 Mutations Altering TIM-3 Characterize Subcutaneous Panniculitis-Like T Cell Lymphomas With Hemophagocytic Lymphohistiocytic Syndrome. Nat Genet (2018) 50(12):1650-7. doi: 10.1038/ s41588-018-0251-4

79. Polprasert C, Takeuchi Y, Kakiuchi N, Yoshida K, Assanasen T, Sitthi W, et al. Frequent Germline Mutations of HAVCR2 in Sporadic Subcutaneous
Panniculitis-Like T-Cell Lymphoma. Blood Adv (2019) 3(4):588-95. doi: 10.1182/bloodadvances.2018028340

80. Rittmeyer A, Barlesi F, Waterkamp D, Park K, Ciardiello F, von Pawel J, et al. Atezolizumab Versus Docetaxel in Patients With Previously Treated NonSmall-Cell Lung Cancer (OAK): A Phase 3, Open-Label, Multicentre Randomised Controlled Trial. Lancet (2017) 389(10066):255-65. doi: 10.1016/S0140-6736(16)32517-X

81. Hellmann MD, Rizvi NA, Goldman JW, Gettinger SN, Borghaei H, Brahmer JR, et al. Nivolumab Plus Ipilimumab as First-Line Treatment for Advanced Non-Small-Cell Lung Cancer (CheckMate 012): Results of an Open-Label, Phase 1, Multicohort Study. Lancet Oncol (2017) 18(1):31-41. doi: 10.1016/ S1470-2045(16)30624-6

82. Weber JS, D'Angelo SP, Minor D, Hodi FS, Gutzmer R, Neyns B, et al. Nivolumab Versus Chemotherapy in Patients With Advanced Melanoma Who Progressed After Anti-CTLA-4 Treatment (CheckMate 037): A Randomised, Controlled, Open-Label, Phase 3 Trial. Lancet Oncol (2015) 16 (4):375-84. doi: 10.1016/S1470-2045(15)70076-8

83. Valsecchi ME. Combined Nivolumab and Ipilimumab or Monotherapy in Untreated Melanoma. New Engl J Med (2015) 373(13):1270. doi: 10.1056/ NEJMc1509660

84. Thoma C. CheckMate for Advanced-Stage ccRCC? Nivolumab and Cabozantinib Ameteorate Poor Survival. Nat Rev Clin Oncol (2015) 12 (12):742. doi: 10.1038/nrclinonc.2015.207

85. Takamura S, Tsuji-Kawahara S, Yagita H, Akiba H, Sakamoto M, Chikaishi T, et al. Premature Terminal Exhaustion of Friend Virus-Specific Effector CD8+ T Cells by Rapid Induction of Multiple Inhibitory Receptors. J Immunol (2010) 184(9):4696-707. doi: 10.4049/jimmunol.0903478

86. Kim JE, Patel MA, Mangraviti A, Kim ES, Theodros D, Velarde E, et al. Combination Therapy With Anti-PD-1, Anti-TIM-3, and Focal Radiation Results in Regression of Murine Gliomas. Clin Cancer Res (2017) 23(1):12436. doi: 10.1158/1078-0432.CCR-15-1535

87. Koyama S, Akbay EA, Li YY, Herter-Sprie GS, Buczkowski KA, Richards WG, et al. Adaptive Resistance to Therapeutic PD-1 Blockade Is Associated With Upregulation of Alternative Immune Checkpoints. Nat Commun (2016) 7:10501. doi: $10.1038 /$ ncomms 10501

88. Curigliano G, Gelderblom H, Mach N, Doi T, Tai D, Forde PM, et al. Phase I/ Ib Clinical Trial of Sabatolimab, an Anti-TIM-3 Antibody, Alone and in Combination With Spartalizumab, an Anti-PD-1 Antibody, in Advanced Solid Tumors. Clin Cancer Res An Off J Am Assoc Cancer Res (2021) 27 (13):3620-9. doi: 10.1158/1078-0432.CCR-20-4746

89. Harding JJ, Moreno V, Bang YJ, Hong MH, Patnaik A, Trigo J, et al. Blocking TIM-3 in Treatment-Refractory Advanced Solid Tumors: A Phase Ia/b Study of LY3321367 With or Without an Anti-PD-L1 Antibody. Clin Cancer Res an Off J Am Assoc Cancer Res (2021) 27(8):2168-78. doi: 10.1158/10780432.CCR-20-4405

90. Hellmann MD, Bivi N, Calderon B, Shimizu T, Delafontaine B, Liu ZT, et al. Safety and Immunogenicity of LY3415244, a Bispecific Antibody Against TIM-3 and PD-L1, in Patients With Advanced Solid Tumors. Clin Cancer Res an Off J Am Assoc Cancer Res (2021) 27(10):2773-81. doi: 10.1158/10780432.CCR-20-3716

91. Acharya N, Sabatos-Peyton C, Anderson AC. Tim-3 Finds Its Place in the Cancer Immunotherapy Landscape. J Immunother Cancer (2020) 8(1): e000911. doi: 10.1136/jitc-2020-000911

92. Schnell A, Bod L, Madi A, Kuchroo VK. The Yin and Yang of Co-Inhibitory Receptors: Toward Anti-Tumor Immunity Without Autoimmunity. Cell Res (2020) 30(4):285-99. doi: 10.1038/s41422-020-0277-x

93. Mueller DL, Jenkins MK, Schwartz RH. Clonal Expansion Versus Functional Clonal Inactivation: A Costimulatory Signalling Pathway Determines the Outcome of T Cell Antigen Receptor Occupancy. Annu Rev Immunol (1989) 7:445-80. doi: 10.1146/annurev.iy.07.040189.002305

94. Bretscher P. Cohn M. A Theory of Self-Nonself Discrimination. Science (1970) 169(3950):1042-9. doi: 10.1126/science.169.3950.1042

95. Chen L, Flies DB. Molecular Mechanisms of T Cell Co-Stimulation and CoInhibition. Nat Rev Immunol (2013) 13(4):227-42. doi: 10.1038/nri3405

96. June CH, Ledbetter JA, Gillespie MM, Lindsten T. Thompson CB. T-Cell Proliferation Involving the CD28 Pathway Is Associated With CyclosporineResistant Interleukin 2 Gene Expression. Mol Cell Biol (1987) 7(12):4472-81. doi: $10.1128 / \mathrm{mcb} .7 .12 .4472-4481.1987$ 
97. Chang E, Pelosof L, Lemery S, Gong Y, Goldberg KB, Farrell AT, et al. Systematic Review of PD-1/PD-L1 Inhibitors in Oncology: From Personalized Medicine to Public Health. Oncology (2021) 26:1-14. doi: 10.1002/onco.13887

98. Kon E, Benhar I. Immune Checkpoint Inhibitor Combinations: Current Efforts and Important Aspects for Success. Drug Resist Updates Rev Commentaries Antimicrob Anticancer Chemother (2019) 45:13-29. doi: 10.1016/j.drup.2019.07.004

Conflict of Interest: The authors declare that the research was conducted in the absence of any commercial or financial relationships that could be construed as a potential conflict of interest.
Publisher's Note: All claims expressed in this article are solely those of the authors and do not necessarily represent those of their affiliated organizations, or those of the publisher, the editors and the reviewers. Any product that may be evaluated in this article, or claim that may be made by its manufacturer, is not guaranteed or endorsed by the publisher.

Copyright $\odot 2021$ Tian and Li. This is an open-access article distributed under the terms of the Creative Commons Attribution License (CC BY). The use, distribution or reproduction in other forums is permitted, provided the original author(s) and the copyright owner(s) are credited and that the original publication in this journal is cited, in accordance with accepted academic practice. No use, distribution or reproduction is permitted which does not comply with these terms. 